\title{
Intestinal Infarctus following Dilatation and Uterine Curettage
}

\author{
N.M. Ngowe R. Atangana V.C. Eyenga M.A. Sosso
}

Department of Surgery and Specialties, Faculty of Medicine and Biomedical Sciences, Surgical Unit, General Hospital, Yaounde, Cameroon

\section{Key Words}

Intestinal infarctus $\cdot$ Abortion

\begin{abstract}
We present a case of intestinal infarctus through the vagina. This was a consequence of induced abortion done clandestinely. The main objective was to point out the surgical complications of uterine dilatation and curettage by means of this rare case.
\end{abstract}

\section{Introduction}

Induced abortion is practised clandestinely in Cameroon. Among the various procedures, uterine dilatation and curettage (D and $C$ ) goes with many complications $[1$, 2]. We report this case of an intestinal infarctus through the vagina, a rare phenomenon seen for the first time in our unit since 10 years, with the aim of depicting a surgical complication of D and C.

\section{Case Report}

Mrs NC, 34 years, G6P5015, presented for acute pelvic pain and a mass between the thighs. She had had a clandestine D and C 4 hours before after 7 weeks of amenorrhea. On entry, she had a BP of 90/50 $\mathrm{mm} \mathrm{Hg}$, a pulse of $92 / \mathrm{min}$, a temperature of $37^{\circ} \mathrm{C}$ and pale conjunctivae. On clinical assay, there was a cold, dark intestinal mass between the thighs with no mesenteric pulsations (fig. 1). There was a globular uterus with diffuse abdominal tenderness; vaginal exam confirmed an intestinal mass. Biological exams showed anemia with hemoglobin $9.9 \mathrm{~g} / \mathrm{l}$ and hemocrit of $29 \%$.On this basis a laparotomy was done after a $6 \mathrm{~h}$ reanimation. We found a posterior uterine perforation $5 \mathrm{~cm}$ long, a hernia of the ileo-cecal junction with necrosis at the basis of the cecum; the proximal ileum which was engaged in the vagina and between the thighs was infarcted. Treatment consisted of resection of the exteriorized part, right hemicolectomy with ileo-transverse termino-lateral anastomosis, uterine suture with separate points with Polyglactin 910. The patient was discharged a week later. She has been feeling well since. 


\section{Discussion}

Induced abortion is associated with many complications which necessitate continuous surveillance all over the world [3]. Some of those complications can lead to generalised peritonitis [4], thus affecting the abdominal cavity. In our case, we had a vascular complication due to ischemia of the bowel which was outside the abdominal cavity. This is the first time we encountered such a complication in our unit. Such lesions have been described in cases of delayed strangulated hernias. The treatment consists classically on resection - anastomosis of the infarcted part of the intestine [5]. That was done in our case.

\section{Conclusion}

We have reported a complication of induced abortion which resulted in intestinal resection due to intestinal infarctus. This is a rare phenomenon observed in developing countries.

Fig. 1. Intestinal infarctus.

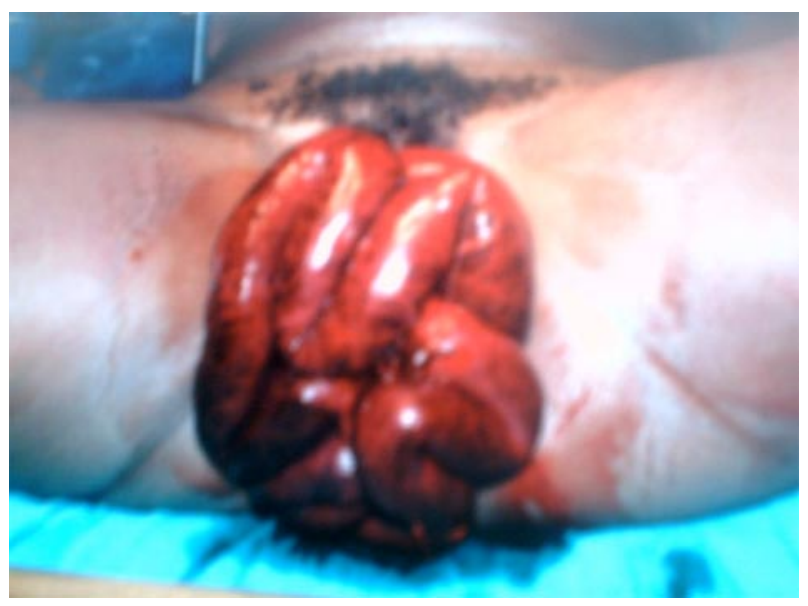




\section{References}

1 Aboyeji MP, Fawole AA: Complications from unsafe abortion, presentation in Ilorin (Nigeria). Niger J Med 2002;11:77-80.

2 Diallo FS, Traore M, Diakite S: Complications from abortion in Bamako (Mali). Santé 2000;10:243-247.

-3 Herndon J, Strauss LT, Whitehead S, at al: Abortion surveillance - United States, 1998. MMWR Surveill Summ 2002;51:1-32.

4 Takongmo S, Binam F, Simeu C, Ngassa P, Kouam L, Malonga E: Aspects thérapeutiques des péritonites génitales au CHU de Yaoundé. Med Afr Noire 2000;47:19-21.

5 Menegaux F: Strangulated hernias; in Carli P, Riou B, Télion C (eds): Urgences médico-chirurgicales. Paris, Arnette, 2004, pp 520-522. 